\title{
REGISTRATION OF THE EMISSION OF SUBMICRON PARTICLES OF ROCKS TO PREDICT THE DESTRUCTION OF UNDERGROUND MINE WORKINGS AT ROCKBURST-HAZARDOUS DEPOSITS
}

S.D. Viktorov

A.A. Osokin

A.V. Shlyapin

I.N. Lapikov victorov_s@mail.ru

osokin_alex-r@mail.ru

shlyapin@mail.ru

itwent@gmail.com

Institute of Comprehensive Exploitation of Mineral Resources,

Russian Academy of Sciences (ICEMR RAS), Moscow, Russian Federation

\begin{abstract}
The results of studies of the conditions for the formation of submicron particles from the surface of the rock formation under the influence of external factors are presented. The deformation and destruction of the mass of rock formations under the conditions of anthropogenic activity under the influence of rock pressure and blasting are characterized by the origin and development of structural defects at various scale levels. A method for recording the emission of submicron particles is proposed to carry out experimental work forstudies of the process of disintegration and the formation of free particles. The results of laboratory studies of the stress-strain state of rock formation samples with a through cylindrical cavity under uniaxial compression, made on the basis of a physical model for the formation of submicron particles from the surface of the samples under study, are presented. The sizes and nature of changes in stress concentration zones and fracture under quasi-static uniaxial loading of specimens are determined. The loading limits have been established to ensure the transfer of rock formation samples to the pre-fracture state. The obtained results are necessary for the development of a fundamentally new method and hardware-technical base for recording dynamic forms of manifestation of rock pressure and prediction of rockbursts in the conduct of underground mining. The results of experimental-industrial tests of the method for determining the stress-strain state of a specific section of a rock formation massif based on the phenomenon of submicron particle emission are presented
\end{abstract}

Keywords

Registration, emission, submicron particle, rock formation, rockburst-hazardous deposits, prediction, destruction

Received 10.12.2018

(c) Author(s), 2019 
Registration of the Emission of Submicron Particles of Rocks to Predict the Destruction...

Introduction. In the last decade, the modern development of the scientific research base provides an opportunity to study in detail the physical processes at all dimensional levels [1-5]. Technological processes for the extraction of minerals by the underground method depend on a variety of geophysical factors and require the prompt assessment of the state of the environment to ensure the safe and efficient extraction of mineral raw materials [6-8]. The increase in the scope of mining is directly related to the increased risk of the appearance of catastrophic situations in mining enterprises. With an increase in the depth of development, difficulties arise during the transportation of broken rock, ventilation of mine workings, operation of mining equipment, etc. Under the influence of static and dynamic loads, the rockformations around the workings pass into a state of extreme deformation and are destroyed under conditions of heterogeneous stress conditions [9-11]. In this regard, the safety of mining operations is of particular importance in the development of deposits at great depths and in difficult mining and geological conditions.

The results of theoretical and experimental laboratory studies of the formation of submicron particles during deformation and destruction of rock formations, made in ICEMR RAS, became the basis for developing a method for predicting catastrophic phenomena in the conduct of underground mining.

Theoretical prerequisites for the formation of nanoscale particles during deformation and destruction of rock formations. The phenomenon of separation of rock fragments from the outcrop surface is a consequence of the high internal energy of the geomaterial. On the scale of macro fracture, it is well known as the phenomenon of "shooting" and peeling of rocks from the walls of mine workings, and on the microscopic scale as fracture emission, shear, and separation of micro- and nanostructured fragments [12-14]. Similar phenomena are characteristic of other materials, in particular, metals [15].

It is known that mechanical testing of rock formations is one of the most important types of research that allow you to determine their ability to resist deformation and destruction under the influence of external loads. It should be noted that through a cylindrical cavity in the sample is an important feature of these studies. It is an artificial macroscopic heterogeneity, the dimensions of which can be varied, and serves as a stress concentrator under uniaxial compression of the sample, which allows fixing the beginning of the process of microfracture of the cavity surface at an early stage of loading. In addition, this design ensures the tightness of the measuring scope of the cavity from particles from the environment.

The performed laboratory studies are aimed at studying the conditions for the formation of submicron particles under various loading conditions. The 
S.D. Viktorov, A.A. Osokin, A.V. Shlyapin, I.N. Lapikov

scope of the research included samples of cylindrical ferruginous quartzite, subjected to uniaxial compression at a load of $P=0-270 \mathrm{kN}$ in four types of loading and several cycles, the number of which was chosen depending on the loading rate. The first three types of loading suggested stepwise uniaxial compression of specimens with fixed loading steps of 15,30 , and $45 \mathrm{kN}$, respectively. The loading time of one stage was a constant parameter and was $10 \mathrm{~s}$. The loading rate for the three types of tests $1.5,3.0$ and $4.5 \mathrm{kN} / \mathrm{s}$. After each load cycle, the sample remained in a static state for $60 \mathrm{~s}$. Such an approach made it possible to monitor the dynamics of particle formation not only with an increase in the load applied to the sample but also under conditions of static uniaxial compression during the entire test time.

For the conditions of the laboratory studies, new qualitative and quantitative general factors for the emission of submicron particles for various types of loading were determined. It has been established that for a species with the lowest loading rate of $1.5 \mathrm{kN} / \mathrm{s}$, the emission increase, amounting to dozens of submicron particles, starts at a load $P=(0.3-0.5) P^{\star}$, where $P^{\star}$ is the limit value of the load. The load (0.5-0.7) $P^{\star}$ is accompanied by the ejection of hundreds of particles, and under a load $(0.80-0.95) P^{\star}$ thousands and tens of thousands of particles are formed. Under conditions with the fastest loading rate of $4.5 \mathrm{kN} / \mathrm{s}$, the emission growth is significant, even at a lower load of $0.25 P^{\star}$ hundreds of particles were recorded, at $0.5 P^{\star}$ the number of particles reached thousands, and at $0.75 P^{\star}$ tens of thousands. For conditions with a loading rate of $3.0 \mathrm{kN} / \mathrm{s}$, quantitative results are intermediate between the above two types of loading. The fourth type of loading implied the load of the sample with a constant rate of $28.5 \mathrm{kN} / \mathrm{min}$ from zero to the decomposition of the sample; particles were recorded at a load of (0.4$0.8) P^{\star}$ with a sharp increase in their number at a load $(0.90-0.95) P^{\star}$. The results of studies of the emission of submicron particles under uniaxial compression and various types of loading are shown in Fig. 1.

The following is established:

- the beginning of emission of submicron particles, its intensity and dynamics depend on the rate of uniaxial stepwise loading of samples, which is explained by the energy required for the growth of existing microcracks and the formation of new ones, this leads to the disintegration of rock formations on the surface of a cylindrical hole;

- peak emission values of submicron particles with stepwise uniaxial loading correspond to the moment of increasing load, which is a consequence of the growth and redistribution of stresses along the contour of the cylindrical hole;

- the method of evaluation of the stress-strain state of rock formation samples by the emission of submicron particles is highly sensitive to external 
Registration of the Emission of Submicron Particles of Rocks to Predict the Destruction...

influences, which allows to register the beginning of the process of rock formation destruction and to control its dynamics in the process of loading;

- the intensity of particle emission is a criterion for the variation of the stress-strain state of the rock sample under quasi-static loading and is characterized by an exponential dependence on the loading, and is also an indicator of the approaching macro fracture of the sample;

- a decrease in the emission of submicron particles under cyclic dynamic effects on rock formation samples is explained by the initial uncovering of existing microcracks and the need for energy storage to form new surfaces.
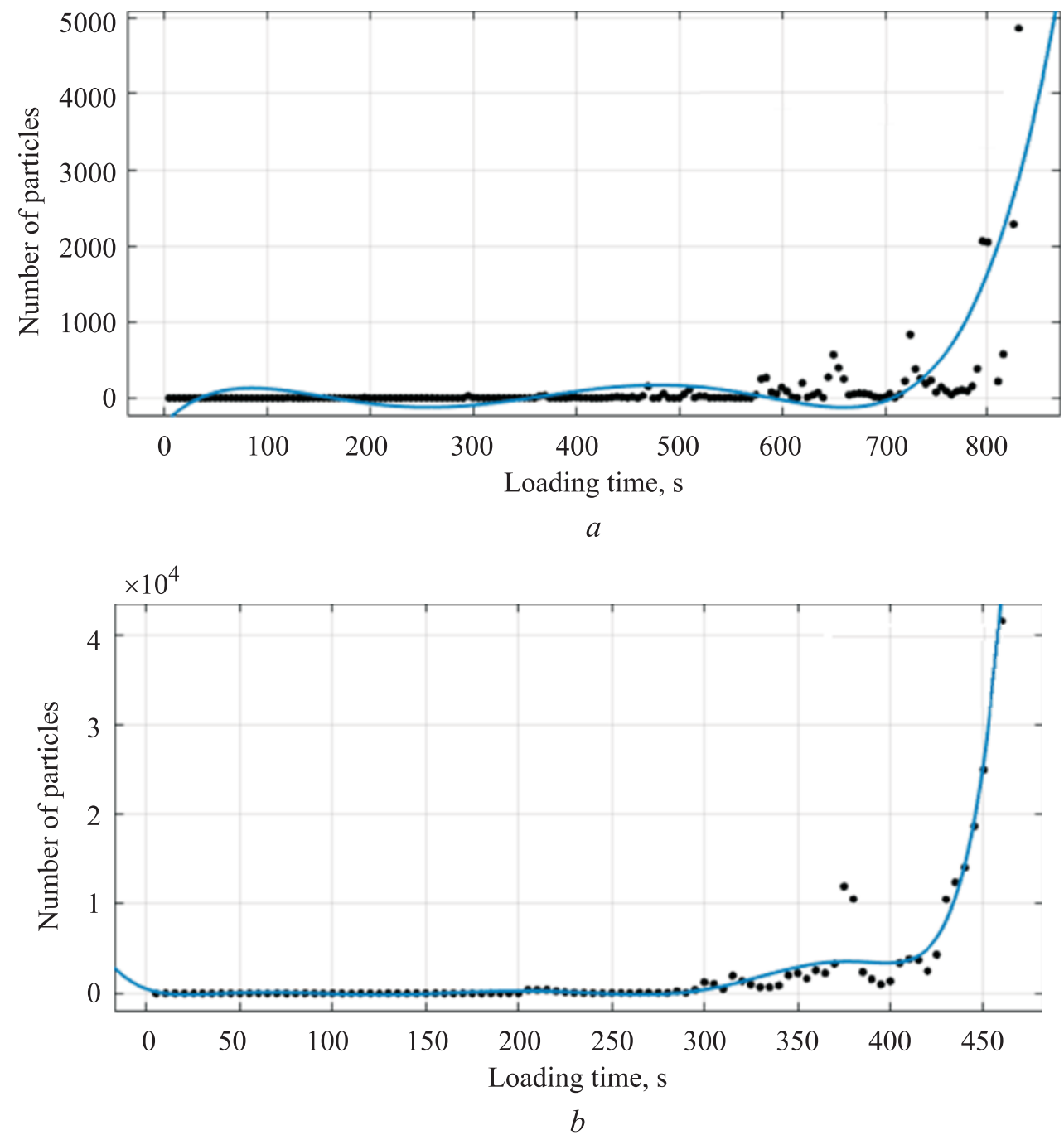

Fig. 1. The results of studies of the emission of nanoparticles when testing samples of ferruginous quartzites with step loading at a rate of $1.5 \mathrm{kN} / \mathrm{s}(a)$ and with a constant loading rate of $0.475 \mathrm{kN} / \mathrm{s}(b)$ 
S.D. Viktorov, A.A. Osokin, A.V. Shlyapin, I.N. Lapikov

The conducted studies prove the dependence of the emission of submicron particles on the quasistatic and dynamic loading of rockformation samples and serve as the basis for the development of a new method for predicting manmade accidents under the influence of external factors during underground mining of mineral deposits based on further selection of particle emission criteria for uncontrolled decomposition of a rock formation mass.

The control method of the stress-strain state, based on recording the radiation of submicron particles, is radically different from other known methods, such as acoustic emission, electromagnetic radiation, infrared radiation, etc. [16-18], which are informative at the preliminary stage of deformation of the test sample. The advantage of this method is the ability to analyze the process of decomposition (rock formation decay) and judge the degree of rock formation decay (this method can be used to work with decaying material). An assessment of the stresses of the medium in the area of preliminary deformation can be carried out according to the state of decay on the walls of the cylindrical hole, where the stresses are 3 times higher than the rock strength. With regard to field conditions, local application of this method is possible in areas with high tectonic stresses, in the reference pressure zone (where primitive rock formation is in a state of out-of-scale deformation, and decomposition comes with varying degrees of disintegration), etc.

Analysis of studies of the formation of submicron particles and the method of their registration showed that the state of destruction of the sample is accompanied by a sharp increase in particle emission, which indicates rapid destruction. Thus, the proposed method will allow increasing the reliability of predictions of dangerous dynamic phenomena in mining when used along with other known methods.

Simulation of conditions for conducting experiments and pilot-scale research, analysis of the results obtained. To assess the effect of tectonic stresses on the walls of the mine workings, a finite element simulation was performed using the ANSYS software package. The following rock formation properties are specified: density $3900 \mathrm{~kg} / \mathrm{m}^{3}$; Young modulus $116.7 \mathrm{GPa}$; Poisson's ratio 0.33 ; bulk modulus of elasticity of $114.4 \mathrm{GPa}$; shear modulus 43.872 GPa; production of a vaulted shape $3 \mathrm{~m}$ wide and $3 \mathrm{~m}$ high.

In both walls with a pitch of $2.5 \mathrm{~m}$, along the mine workings, the horizontal blast-holes with a diameter of $32 \mathrm{~mm}$ were drilled at a distance of 0.5 and $1.0 \mathrm{~m}$ from the floor. Vertical blast-holes with a diameter of $32 \mathrm{~mm}$ were drilled in the fornix of the mine workings. The load on the walls of the mine workings on both sides (pressure $150 \mathrm{MPa}$ ) was set.

54 ISSN 1812-3368. Вестник МГТУ им. Н.Э. Баумана. Сер. Естественные науки. 2019. № 5 
Registration of the Emission of Submicron Particles of Rocks to Predict the Destruction...

View of the hole collar of a horizontal blast-hole drilled at a distance of $1 \mathrm{~m}$ from the floor, its horizontal and vertical sections are shown in Fig. 2. Under the influence of the load in the hole collar of the blast-hole, tensile (up to $506 \mathrm{MPa}$ ) and compressive (up to $37 \mathrm{MPa}$ ) stresses arise in the hole of the hole.

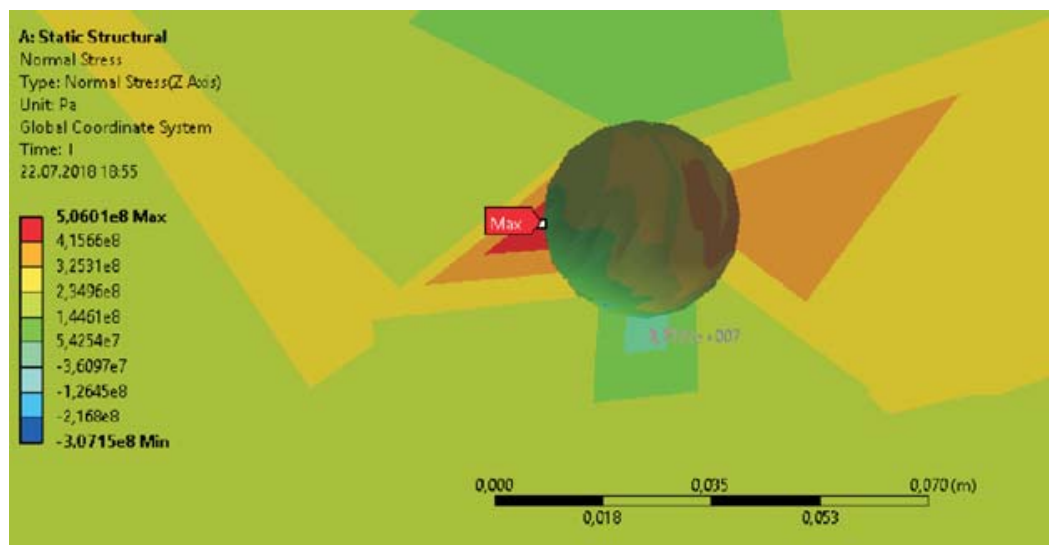

$a$

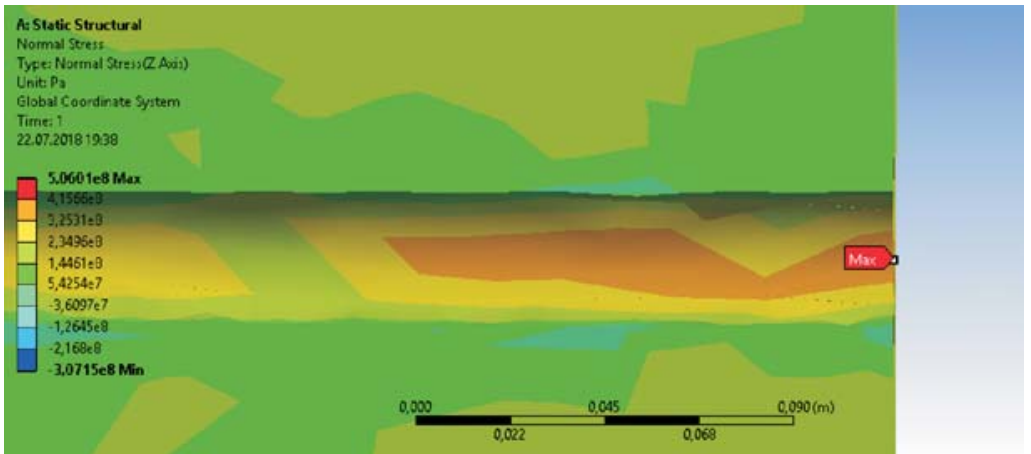

$b$

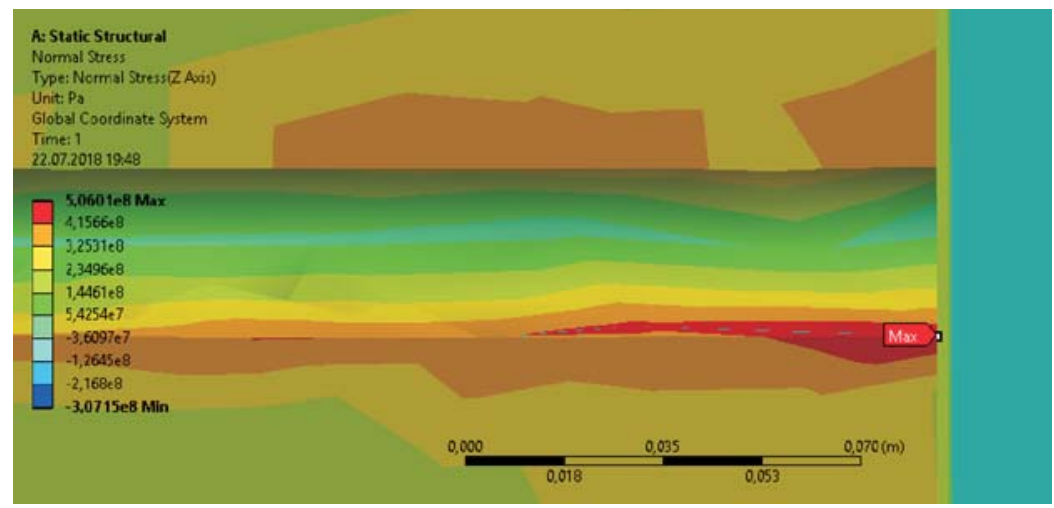

$c$

Fig. 2. View of the hole collar of a horizontal blast-hole (a), its vertical $(b)$ and horizontal $(c)$ sections 
S.D. Viktorov, A.A. Osokin, A.V. Shlyapin, I.N. Lapikov

A similar picture is also observed under the uniaxial quasi-static loading of a rock specimen $[19,20]$. Since the values of tensile stresses significantly exceed the ultimate tensile strength for ferruginous quartzite $\left(\sigma_{\mathrm{p}}=15 \mathrm{MPa}\right)$, disturbances can form at the places where these stresses are concentrated, which can lead to the emission of particles that serve as a precursor of the dynamic destruction of the rock.

The opposite pattern is observed in the vertical blast-hole drilled in the roof of production: compressive stresses exceed tensile strength by almost two orders of magnitude, reaching 1.5 GPa and $30 \mathrm{MPa}$ (Fig. 3). Since tensile stresses here are 2 times greater than the tensile strength, violations can also form in these zones, leading to the formation of submicron particles and their emission.

Blast-holes (see Fig. 2 and Fig. 3), drilled both in the wall and in the roof of the mine working, are a zone of concentration of tensile stresses in the rock formation exposed to strong tectonic stresses and due to the emission of submicron particles, including those caused by external dynamic effects can be an indicator of the likely development of dynamic phenomena, including rockbursts.

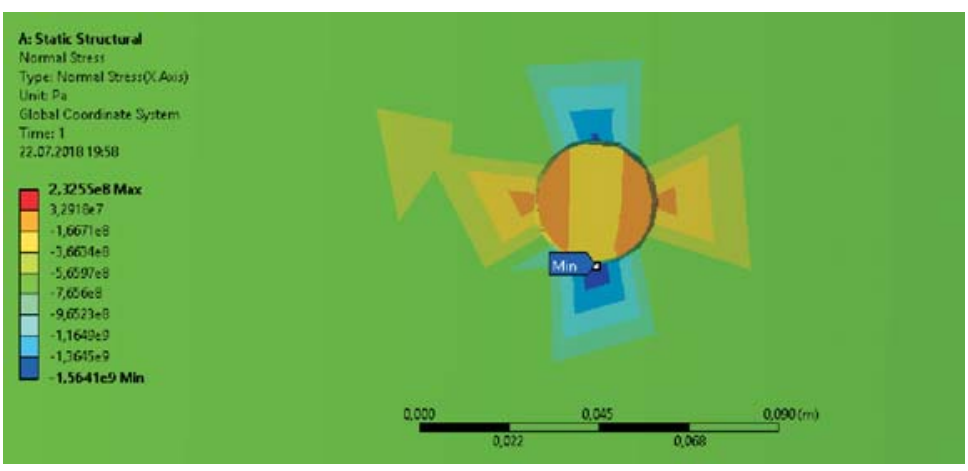

$a$

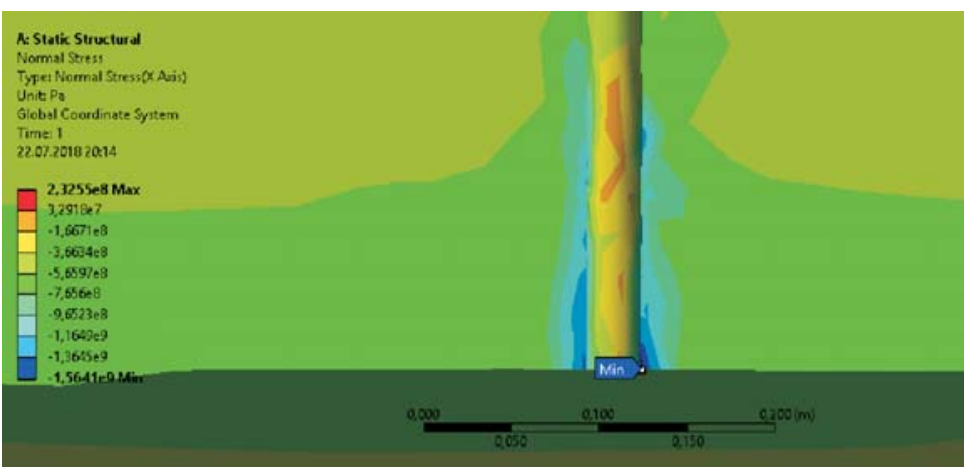

$b$

Fig. 3 (Part 1). View of a hole-collar vertical blast-hole (a), it's cut perpendicular $(b)$ to loading axis 


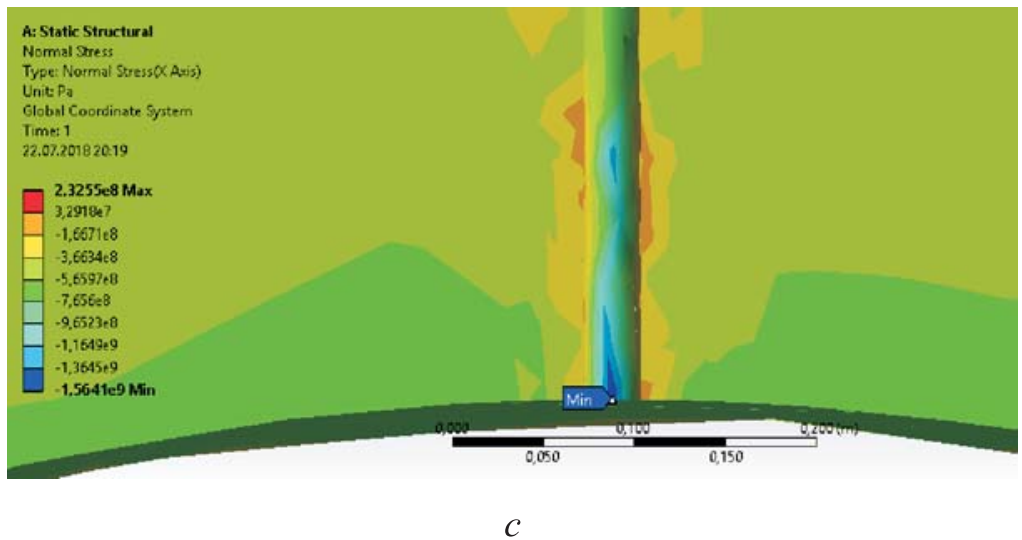

Fig. 3 (Part 2). View of a hole-collar vertical parallel (c) to loading axis

To carry out field studies, a "Program and methodology for conducting pilot-scale studies of the emission of submicron particles in underground mines prone and dangerous to rockbursts for predicting emergencies" has been developed.

Pilot-scale studies of the emission of submicron particles were carried out at the Oleniy Ruchey deposit located in the extreme southeastern part of the Khibiny massif in the valleys of the Mineral Ruchey and Oleniy Ruchey at a distance of $22 \mathrm{~km}$ from the city of Kirovsk (Murmansk Region). The geomechanical state of the Khibiny massif is characterized by a highly inhomogeneous stress-strain state. One of the main factors of accumulation and relaxation of stresses in the massif (when a certain level is reached) in the form of dynamic forms of rock pressure of high energy class, related to man-made earthquakes, is a large amount of seized and displaced rock mass at the Khibiny mines. Analysis of the locations of the foci of these events showed that the rocktectonic bursts and man-made earthquakes occur near zones of tectonic disturbances, oxidized zones and faults, are grouped in the field of mining. In the course of geodynamic studies at the Khibiny mines, more than 70 rockburst were recorded, which are divided into two types:

1) single, when the scope of rock dump is less than $5 \mathrm{~m}^{3}$ and the linear size of the disturbed zone is less than $10 \mathrm{~m}$;

2) rockbursts and man-made earthquakes, the values of the parameters of the area of destruction for which are much higher.

The separation of rockbursts into two types is associated with both the scope of dumps and the size of the disturbed zone, as well as the various mechanisms established for these phenomena. At the same time, both explosive faults and internal progress (shifts and cleaves) manifested within the minefields of the 
S.D. Viktorov, A.A. Osokin, A.V. Shlyapin, I.N. Lapikov

mined deposits are sources of seismic signals. Such phenomena are the main destabilizing factor in mining at the Khibiny mines.

To conduct pilot-scale studies of the emission of submicron particles at the Oleniy Ruchey deposit, an underground mine working was chosen (lateral drift of the horizon +140$)$. Six blast-holes with a diameter of $42-45 \mathrm{~mm}$ and a depth of $1 \mathrm{~m}$ were drilled in the wall of the mineworkings. Blast-holes were located at a height of $1.5 \mathrm{~m}$ from the base of the mine working in $3 \mathrm{~m}$ steps from each other and were cleaned in advance of the drilling fines generated during drilling. The object of research is the blast-holes in which the measuring probe is installed. To isolate the blast-hole scope from the fine particles of the mine atmosphere, a sealant and a high-performance air filter are used that do not let in particles larger than $100 \mathrm{~nm}$. The Hand Held 3016 aerosol particle counter was used to measure the emission of submicron particles, which allows continuous registration of particles in six-dimensional ranges in the range of $0.3-5.0 \mu \mathrm{m}$ and more than $5 \mu \mathrm{m}$.

The studies were performed in three stages.

1. Registration of particle emission in each blast-hole for $10 \mathrm{~min}$.

2. Daily analysis of each blast-hole.

3. Study for 20 days.

At the first stage, preliminary results of the emission intensity of submicron particles in six blast-holes were obtained. The second stage is aimed at more detailed monitoring within 24 hours. The final stage was the long-term monitoring of the blast-hole, located in the most dangerous part of the mineworking, representing the potential danger of a sudden collapse of the rock formation.

In the process of analyzing the results of the first stage of registration, it was established that the emission of particles in blast-hole No. 5 significantly exceeds the emission values in other blast-holes, and the emission intensity in the largest range (particles larger than 5 microns) exceeds on average two orders of magnitude compared to with intensity in other blast-holes. The histogram of the results of the emission of submicron particles obtained at the first stage for six blast-holes is shown in Fig. 4 (measurement period $10 \mathrm{~min}$ ).

The results indicate the evolving blast-hole destruction process, which is characterized by the formation of a new particle of micron and submicron sizes.

Longer measurements of the emission of submicron particles of the second and third stages confirmed the feasibility of using this approach to identify local potentially dangerous areas of underground mine workings on the basis of drilling blast-holes and registering the emission of submicron particles.

It is obvious that man-made human activity associated with the extraction of minerals leads to a change in the natural stress state of the rock formations. 
Registration of the Emission of Submicron Particles of Rocks to Predict the Destruction...

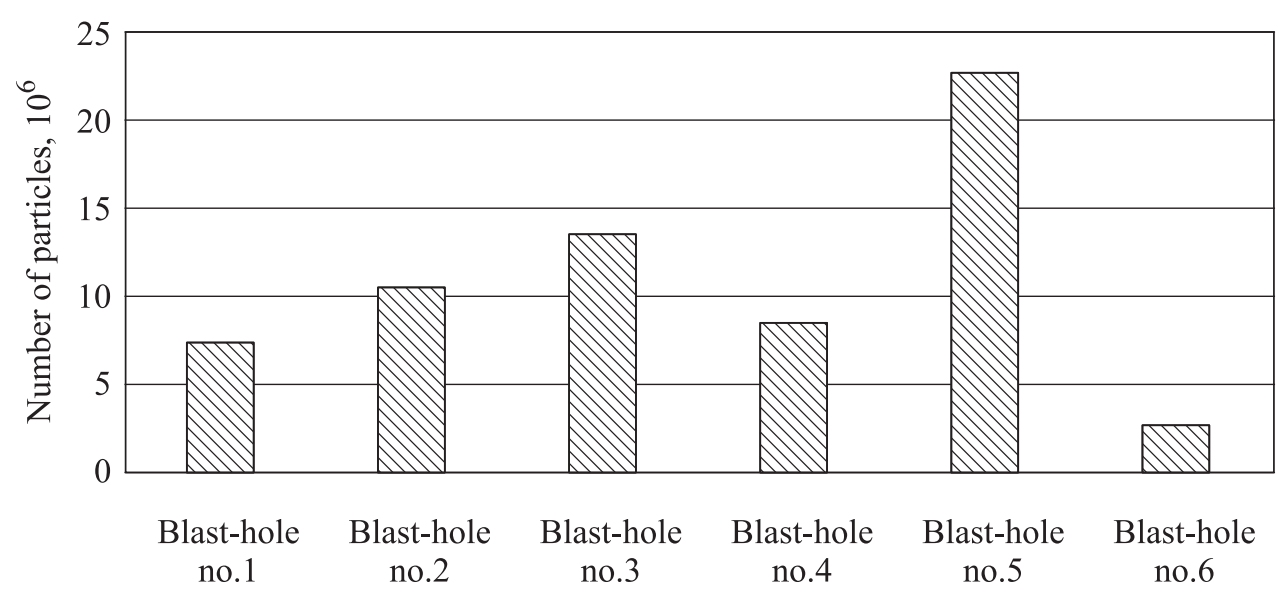

Fig. 4. Results of particle emission at the first stage of registration

When creating artificial cavities (mine workings) in the rock massif, redistribution of stresses occurs, which concentrate on the contour of the mine workings and are caused by various geological and geomechanical factors (stress distribution in the massif, the ratio of vertical and horizontal stresses, effective stresses, heterogeneity, fracturing, etc.). Rock formation near the mine workings are often in a state of extreme deformation and may be accompanied by the separation of individual fragments from its surface, which characterizes the degree of tension of a certain section of mine workings.

In order to improve the safety of mine workings at the Oleniy Ruchey field, preventive measures are widely used to identify weak areas of mine workings with the subsequent collapse of individual pieces of a rock formation using mechanized dynamic effects. Then carry out the fixing of mine workings by spraying with concrete, which in general allows to significantly increase the stability of the mine workings. However, these activities do not preclude the occurrence of dangerous situations associated with the sudden destruction of rock formations, especially in rockburst-hazardous deposits.

The increase in rock scope and the development of cracks (rock formation dilatancy) due to inhomogeneous volumetric compression near mine workings is a fairly well-known phenomenon, often manifested at great depths and in seismically dangerous mining areas, which increases the risk of accidents at mining enterprises. Thus, the developed method allows at an early stage to assess and identify local potentially dangerous areas of underground mine workings based on drilling blast-holes and registering the emission of submicron particles.

Possessing high sensitivity, the method of recording the emission of submicron particles is of great interest for evaluating relatively safe areas that are in a static state and, as a rule, do not pose a particular threat, but have a high 
S.D. Viktorov, A.A. Osokin, A.V. Shlyapin, I.N. Lapikov

probability of being activated in the case of even small dynamic forms of rock pressure, which in the future may be a potential danger not only for people in the mine workings, but also for expensive equipment, as well as lead to downtime of mining enterprises. The above causes significant economic damage to the country's mining industry.

Recommendations and conclusions. Analysis of the results of laboratory and industrial tests allowed to develop recommendations aimed at obtaining more operational information about the stressed part of the massif, namely:

- in contrast to laboratory tests for field tests, it is necessary to use a device with a higher blast-hole air take-off rate, which is associated with the analyzed scope, which is much larger than during laboratory tests, this will allow to more quickly evaluate the dynamics of submicron particle emission when surface of blast-hole is destroyed-hole due to its deformation under conditions of high stresses and the development of cracks;

- the need for additional industrial research will allow identifying the most informative dimensional ranges, which is a prerequisite at the development stage of the technical specifications of the recording complex designed for monitoring the emission of submicron particles.

In contrast to the existing methods for estimating the stress-strain state (method of acoustic emission, electromagnetic emission, infrared radiation), the developed method allows you to work directly with a disintegrated material that is in a state of extreme deformation. In natural conditions, where there are large tectonic stresses, for example, in the reference pressure zone, the rock massif is in a state of extreme deformation and the process of destruction proceeds with different degrees of disintegration. In addition, the studies performed indicate a high sensitivity of the developed method, which in perspective using wellknown methods for assessing the stress-strain state will allow obtaining more reliable information about the rock massif, detecting hazardous areas in advance and making decisions about taking appropriate measures.

Translated by K. Zukova

\section{REFERENCES}

[1] Viktorov S.D., Kochanov A.N., Osokin A.A. Emission of microparticles at deformation and destruction of samples of rocks in the conditions of uniaxial compression. Tambov University Reports. Series: Natural and Technical Sciences, 2010, vol. 15, no. 3-2, pp. 1163-1164 (in Russ.).

[2] Chanturiya V.A., Trubetskoy K.N., Viktorov S.D., et al. Nanochastitsy v protsessakh razrusheniya i vskrytiya geomaterialov [Nanoparticles in processes of geomaterials destruction and extraction]. Moscow, IPKON RAN Publ., 2006. 
Registration of the Emission of Submicron Particles of Rocks to Predict the Destruction...

[3] Trubetskoy K.N., Viktorov S.D., Osokin A.A., et al. Rockburst prediction based on submicron particle emission in rocks under deformation and failure. Gornyi zhurnal, 2017, no. 6, pp. 16-20 (in Russ.). DOI: 10.17580/gzh.2017.06.03

[4] Isheyskiy V.A., Marinin M.A. Determination of rock mass weakening coefficient after blasting in various fracture zones. Eng. Solid Mech., 2017, vol. 5, no. 3, pp. 199-204.

DOI: 10.5267/j.esm.2017.4.001

[5] Isheyskiy V.A., Yakubovskiy M.M. Determination of strength reduction factor in blasted rocks versus the distance from the blast center. Gornyi zhurnal, 2016, no. 12, pp. 55-59 (in Russ.). DOI: 10.17580/gzh.2016.12.12

[6] Kurlenya M.V., Eremenko A.A., Shrepp B.V. Geomekhanicheskie problemy razrabotki zhelezorudnykh mestorozhdeniy Sibiri [Geomechanical problems of Siberia iron-ore deposits exploitation]. Novosibirsk, Nauka Publ., 2001.

[7] Eremenko V.A. Natural and man-caused factors of development of mining strikes in the development of iron ore deposits in Western Siberia. Gornyy informatsionnoanaliticheskiy byulleten [Mining Informational and Analytical Bulletin], 2012, no. 11, pp. 50-59 (in Russ.).

[8] Maleki H., Lawson H. Analysis of geomechanical factors affecting rock bursts in sedimentary rock formations. Procedia Eng., 2017, vol. 191, pp. 82-88.

DOI: https://doi.org/10.1016/j.proeng.2017.05.157

[9] Kaiser P.K., Cai M. Design of rock support system under rockburst condition. JRMGE, 2012, vol. 4, iss. 3, pp. 215-227. DOI: https://doi.org/10.3724/SP.J.1235.2012.00215

[10] Tripathy G.R., Shirke R.R., Kudale M.D. Safety of engineered structures against blast vibrations: a case study. JRMGE, 2016, vol. 8, iss. 2, pp. 248-255.

DOI: https://doi.org/10.1016/j.jrmge.2015.10.007

[11] Mazaira A., Konicek P. Intense rockburst impacts in deep underground construction and their prevention. CGJ, 2015, vol. 52, no. 10, pp. 1426-1439.

DOI: https://doi.org/10.1139/cgj-2014-0359

[12] Kabwe E., Wang Y. Review on rockburst theory and types of rock support in rockburst prone mines. OJSST, 2015, vol. 5, no. 4, pp. 104-121.

DOI: http://dx.doi.org/10.4236/ojsst.2015.54013

[13] Massalimov I.A., Urakaev F.Kh. [On possibility of nanoparticles formation in a crack corner]. Fizikokhimiya ultradispersnykh (nano-) system. Mat. VI Vseros. mezhdunar. konf. [Physicochemistry of ultra-disperse (nano-) system. Proc. VI Russ. Int. Conf.]. Moscow, MEPhI Publ., 2002, pp. 46-47 (in Russ.).

[14] Odintsev V.N. Otryvnoe razrushenie skalnykh gornykh porod [Breakout of rock terrain]. Moscow, IPKON RAN Publ., 1996.

[15] Urakaev F.Kh., Massalimov I.A. Energy fluctuations and particle emission in a crack mouth. Phys. Solid State, 2005, vol. 47, iss. 9, pp. 1675-1680.

DOI: https://doi.org/10.1134/1.2045350

[16] Aleksandrov P.A., Kalechits V.I., Khozyasheva E.S., et al. Study on microparticles generation at metal abruption. Problemy mashinostroeniya i nadezhnosti mashin, 2003, no. 5, pp. 95-98 (in Russ.).

ISSN 1812-3368. Вестник МГТУ им. Н.Э. Баумана. Сер. Естественные науки. 2019. № 5 
S.D. Viktorov, A.A. Osokin, A.V. Shlyapin, I.N. Lapikov

[17] Aker E., Kühn D., Vavryčuk V., et al. Experimental investigation of acoustic emissions and their moment tensors in rock during failure. Int. J. Rock Mech. Min. Sci., 2014, vol. 70, pp. 286-295. DOI: https://doi.org/10.1016/j.ijrmms.2014.05.003

[18] Lacidogna G., Carpinteri A., Manuello A., et al. Acoustic and electromagnetic emissions as precursor phenomena in failure processes. Strain, 2011, vol. 47, iss. s2, pp. 144-152. DOI: https://doi.org/10.1111/j.1475-1305.2010.00750.x

[19] Vostretsov A.G., Krivetsky A.V., Bizyaev A.A., et al. Electromagnetic radiation characteristics of rocks in their destruction in laboratory experiments. Proceedings of the Russian Higher School Academy of Sciences, 2013, no. 2 (21), pp. 46-54 (in Russ.).

[20] Viktorov S.D., Osokin A.A., Shlyapin A.V., et al. Computer modeling of stress concentration zones for estimation of state of geomaterials. Gornyi zhurnal, 2017, no. 11, pp. 41-44 (in Russ.). DOI: 10.17580/gzh.2017.11.08

Viktorov S.D. - Dr. Sc. (Eng.), Professor, Deputy Director, Institute of Comprehensive Exploitation of Mineral Resources, Russian Academy of Sciences (ICEMR RAS) (Kryukovskiy tupik 4, Moscow, 111020 Russian Federation).

Osokin A.A. - Cand. Sc. (Eng.), Senior Researcher, Institute of Comprehensive Exploitation of Mineral Resources, Russian Academy of Sciences (ICEMR RAS) (Kryukovskiy tupik 4, Moscow, 111020 Russian Federation).

Shlyapin A.V. - Cand. Sc. (Eng.), Head of the Department, Institute of Comprehensive Exploitation of Mineral Resources, Russian Academy of Sciences (ICEMR RAS) (Kryukovskiy tupik 4, Moscow, 111020 Russian Federation).

Lapikov I.N. - Cand. Sc. (Eng.), Senior Researcher, Institute of Comprehensive Exploitation of Mineral Resources, Russian Academy of Sciences (ICEMR RAS) (Kryukovskiy tupik 4, Moscow, 111020 Russian Federation).

\section{Please cite this article as:}

Viktorov S.D., Osokin A.A., Shlyapin A.V., et al. Registration of the emission of submicron particles of rocks to predict the destruction of underground mine workings at rockburst-hazardous deposits. Herald of the Bauman Moscow State Technical University, Series Natural Sciences, 2019, no. 5, pp. 50-62.

DOI: $10.18698 / 1812-3368-2019-5-50-62$ 